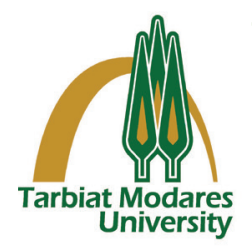

\title{
Study of Antibacterial Activity of Gentamicin-Cetirizine on Uropathogenic Escherichia coli Isolates
}

\section{A R T I C L E I N F O}

Article Type

Original Research

Authors

Leila Hasani, $M S c^{1}$

Leila Fozouni, $P h D^{1^{*}}$
How to cite this article

Hasani L., Fozouni L. Study of An-

tibacterial Activity of Gentamicin-Cetirizine on Uropathogenic Escherichia coli Isolates. Infection Epidemiology and Microbiology. 2021;7(1): 37-43

${ }^{1}$ Department of Biology, Gorgan Branch, Islamic Azad University, Gorgan, Iran

\section{* Correspondence}

Address: Department of Biology, Gorgan Branch, Islamic Azad University, Gorgan, Iran.

Tel:+989111518674

lili_kia@yahoo.com

\section{A B S T R A C T}

Background: Urinary tract infections (UTIs) cause a wide range of infections in individuals; they are common nosocomial infections that have recently become difficult to treat because of the increased emergence of multidrug-resistant bacteria. The present study aimed to determine and compare the minimum inhibitory concentration of gentamicin alone and in combination with cetirizine against Escherichia coli strains isolated from hospitalized patients with UTI.

Materials \& Methods: This study was performed on 76 E. coli strains isolated from a total of 103 samples of patients admitted to three hospitals in Gonbad-e Kavus. Kirby Bauer disk diffusion and broth microdilution tests were used to determine antibiotic susceptibility and the minimum inhibitory concentration (MIC) of gentamicin alone and in combination with cetirizine according to CLSI M100-S25 (2015) criteria.

Findings: Evaluation of the minimum inhibitory concentration of gentamicin-cetirizine combination against $E$. coli isolates showed that none were able to grow at a concentration of $8 \mu \mathrm{g} / \mathrm{mL}$. The concentration of gentamicin in combination with cetirizine, inhibiting $90 \%$ of E. coli isolates $\left(\mathrm{MIC}_{90}\right)$, was $4 \mu \mathrm{g} / \mathrm{mL}$, which was 16 times lower than that of gentamicin alone $\left(\mathrm{MIC}_{90}=64 \mu \mathrm{g} / \mathrm{mL}\right)(p=.02)$.

Conclusion: Gentamicin in combination with cetirizine was found to be more potent in inhibiting E. coli isolates than gentamicin alone. Therefore, the results of this study could provide a clear perspective for dealing with drug-resistant pathogens.

Keywords: Escherichia coli, Drug resistance, Gentamicin, Cetirizine.

\section{CITATION LINKS}

[1] Chew KL, La MV, Lin RT, Teo JW. Colistin and polymyxin B susceptibility ... [2] FloresMireles AL, Walker JN, Capron M, Hultgren SJ. Urinary tract infections: Epidemiology, mechanisms of infection, and treatment options. Nat Rev Microbiol ... [3] Foxman B. The epidemiology of ... [4] Jain S, Khety Z. Changing antimicrobial resistance pattern of isolates from an ICU over a 2 year period. J Assoc Phys ... [5] Nesta B, Spraggon G, Alteri C, Gomes Moriel D, Rosini R, Veggi D, et al. FdeC, a novel broadly conserved Escherichia coli adhesin eliciting protection against urinary tract ... [6] Abdi HA, Rashki A. Comparison of virulence factors distribution in ... [7] Annadurai S, Guhathakurta A, Sa B, Dastidar SG, Roy R, Chakraborty AN. Experimental studies on synergism between aminoglycosides and the antimicrobial anti-inflammatory agent ... . [8] Kalayci S. Antimicrobial properties of various nonantibiotic drugs against microorganisms. J Bioanal Biomed ... [9] Manuselis M. Textbook ... [10] Clinical and Laboratory Standards Institute. M100-S25: Performance standards for antimicrobial 324 susceptibility testing; Twenty-fifth informational supplement. Wayne, PA: Clinical and Laboratory ... [11] Abe CM, Salvador FA, Falsetti IN, Vieira MA, Blanco J, Blanco JE, et al. Uropathogenic Escherichia coli (UPEC) strains may carry virulence properties of ... [12] Pourmand M, Keshtvarz M, Soltan Dallal M, Talebi ... [13] Keikha M, Rava M. Trend of antibiotic resistance of Escherichia coli strains isolated from urinary tract infections in outpatients referring to Nabi Akram hospital in Zahedan. J Paramed Sci Rehabil ... [14] Neamati F, Firoozeh F, Saffary M, Mousavi SGA. The prevalence of uropathogenic E. coli and detection of some virulence genes isolated from patients referred to Kashan Shahid-Beheshti hospital during ... [15] Slavchev G, Pisareva E, Markova N. Virulence of uropathogenic Escherichia ... [16] Asadpour Rahimabadi K, Hashemitabar G, Mojtahedi A. Antibiotic-resistance patterns in E. coli ... [17] Perlmutter JI, Forbes LT, Krysan DJ, Ebsworth M, Colgufoun JM, Wang JL, et al. Repurposing the antihistamine terfenadine for antimicrobial activity against S. aureus. J Med Chem ... [18] Dutta NK, Mazumdar K, Dastidar SG, Park JH. Activity of diclofenac used alone and in combination ... [19] Martins M, Dastidar SG, Fanning S, Kristiansen JE, Molnar J, Pages JM, et al. Potential role of nonantibiotics (helper compounds) inb ... [20] Maji HS, Maji S, Bhattacharya M. An exploratory study on the antimicrobial activity of cetirizine dihydrochloride. Indian ... . [21] Shamooshaki T, Fozouni L. Fluconazole and ibuprofen combination: A potential treatment for mucosal ...
Received: October 29,2020

Accepted: December 25,2020

Published: January 23,2021 


\section{Introduction}

Urinary tract infections (UTIs) are one of the most common infectious diseases, affecting approximately 150 million people worldwide each year. Uropathogenic Escherichia coli (UPEC) is responsible for 70$90 \%$ of UTIs in humans. Most UTIs are nonserious; however, lack of timely diagnosis or treatment could cause serious complications such as urinary tract disorders, uremia, and abortion in pregnant women. UTIs are more common in women than in men, so that about half of women experience this infection at least once in their lifetime. Studies in various communities have shown that among Gram-negative bacilli, E. coli is the most common etiologic cause of UTI ${ }^{[1-2]}$. Treatment of patients with UTI is currently facing the problem of drug-resistance. The basis of proper treatment of patients with UTI is the selection of a suitable antibiotic with high efficiency and effectiveness ${ }^{[3-5] .}$ Unfortunately, excessive and sometimes incorrect use of antibiotics provides the conditions for the survival of bacteria and plays an important role in reducing the efficacy of some antibiotics in treating infections. Among drug-resistant E. coli strains, the prevalence of aminoglycosidesresistant bacterial strains is high. Gentamicin is an aminoglycoside that inhibits protein synthesis. Aminoglycoside presence in the cytosol generally disturbs peptide elongation at the $30 \mathrm{~S}$ ribosomal subunit, giving rise to inaccurate mRNA translation and therefore biosynthesis of proteins [67]. Given these problems, the use of new antimicrobial compounds or the study of the synergistic effects of two antimicrobial compounds is a promising solution for the management of drug-resistance. Cetirizine is an antihistamine with aromatic and piperazine rings, whose effective antimicrobial activity may be attributed to these structural components. Therefore, it is possible that cetirizine could be used as an antimicrobial key to cover microbial resistance and bacterial infections ${ }^{[8]}$.

Objectives: The present study aimed to investigate the synergistic effects of an aminoglycoside (gentamicin) with cetirizine on Uropathogenic E. coli isolates.

\section{Materials and Methods}

Bacterial isolation: Urine samples were collected from 103 patients with UTI in three hospitals in Gonbad-e Kavus, northeast of Iran, from October 2018 to February 2019. The patients, either symptomatic or asymptomatic, were hospitalized for more than five days. Diagnosis of UTI was based on positive urine culture, i.e., the presence of $10^{5}$ colonies in asymptomatic patients and $10^{4}$ colonies in symptomatic patients ${ }^{[9]}$. The specimens were taken from first-morning urine and then cultured on blood agar, eosin methylene blue agar, and MacConkey agar, purchased from Merck Co., Germany. The cultured samples were incubated at $37{ }^{\circ} \mathrm{C}$ for $24-18 \mathrm{hrs}$. E. coli isolates were identified based on Gram staining and biochemical assays, including glucose and lactose fermentation, gas production, indole, Voges-Proskauer, Triple Sugar Iron (TSI) agar, sulfide indole motility, and methyl red tests.

Antibiotic susceptibility: Antibiotic resistance pattern of $E$. coli isolates was determined by the disk diffusion (KirbyBauer) method using the following antibiotic disks: tetracycline $(30 \mu \mathrm{g})$, gentamicin (10 $\mu \mathrm{g})$, ceftriaxone $(30 \mu \mathrm{g})$, ceftazidime $(30 \mu \mathrm{g})$, ofloxacin $(5 \mu \mathrm{g})$, nitrofurantoin $(100 \mu \mathrm{g})$, chloramphenicol $(30 \mu \mathrm{g})$, and nalidixic acid (10 $\mu \mathrm{g})$. All antibiotic disks were purchased from Padtan Teb Co., Iran. The results were analyzed according to the standards described by the Clinical and Laboratory Standards Institute

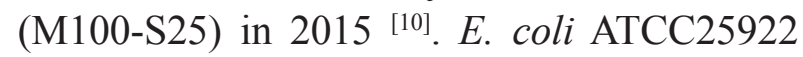
was used as a control. 
Table 1) Antibiotic resistance pattern of E. coli isolates based on the hospital ward

\begin{tabular}{|c|c|c|c|c|c|c|}
\hline Antibiotics & Ward & $\begin{array}{l}\text { Internal } \\
(n=26) \\
N(\%)\end{array}$ & $\begin{array}{l}\text { Surgery } \\
(n=7) \\
N(\%)\end{array}$ & $\begin{array}{l}\text { ICU }(n=29) \\
N(\%)\end{array}$ & $\begin{array}{l}\text { Obstetrics } \\
\text { and } \\
\text { Gynecology } \\
(n=14) \\
N(\%)\end{array}$ & P-Value \\
\hline \multirow{3}{*}{ Tetracycline } & Resistant & $10(38.5)$ & $5(71.4)$ & $7(24.1)$ & $6(42.9)$ & \multirow{3}{*}{.075} \\
\hline & Intermediate & $13(50)$ & - & $18(62.1)$ & $5(35.7)$ & \\
\hline & Susceptible & $3(11.5)$ & $2(28.6)$ & $4(13.8)$ & $3(21.4)$ & \\
\hline \multirow{3}{*}{ Gentamicin } & Resistant & $5(19.2)$ & $3(42.9)$ & $2(6.9)$ & $4(28.6)$ & \multirow{3}{*}{$.026^{*}$} \\
\hline & Intermediate & $13(50)$ & - & $21(72.4)$ & $7(50)$ & \\
\hline & Susceptible & $8(30.8)$ & $4(57.1)$ & $6(20.7)$ & $3(21.4)$ & \\
\hline \multirow{3}{*}{ Ofloxacin } & Resistant & $5(19.2)$ & $1(14.3)$ & $7(24.1)$ & $1(7.1)$ & \multirow{3}{*}{$.038^{*}$} \\
\hline & Intermediate & $12(46.1)$ & $3(42.9)$ & $12(41.4)$ & $5(35.7)$ & \\
\hline & Susceptible & $9(34.6)$ & $3(42.9)$ & $10(34.5)$ & $8(57.1)$ & \\
\hline \multirow{3}{*}{ Ceftazidime } & Resistant & $5(19.2)$ & $1(14.3)$ & $6(20.7)$ & $1(7.1)$ & \multirow{3}{*}{$.01^{*}$} \\
\hline & Intermediate & $5(19.2)$ & $5(71.4)$ & $11(37.9)$ & $5(35.7)$ & \\
\hline & Susceptible & $16(61.5)$ & $1(14.3)$ & $12(41.4)$ & $8(57.1)$ & \\
\hline \multirow{3}{*}{ Ceftriaxone } & Resistant & $6(23.1)$ & $1(14.3)$ & $9(31.1)$ & $2(14.3)$ & \multirow{3}{*}{$.02 *$} \\
\hline & Intermediate & $10(38.5)$ & $3(42.9)$ & $10(34.5)$ & $5(35.7)$ & \\
\hline & Susceptible & $16(61.5)$ & $3(42.9)$ & $10(34.5)$ & $7(50)$ & \\
\hline \multirow{3}{*}{ Chloramphenicol } & Resistant & $9(34.6)$ & $3(42.9)$ & $11(37.9)$ & $5(35.7)$ & \multirow{3}{*}{.066} \\
\hline & Intermediate & 11 & $2(28.6)$ & $11(37.9)$ & $2(14.3)$ & \\
\hline & Susceptible & $6(23.1)$ & $2(28.6)$ & $7(24.1)$ & $7(50)$ & \\
\hline \multirow{3}{*}{ Nalidixic acid } & Resistant & $9(34.6)$ & $4(57.1)$ & $14(48.3)$ & $7(50)$ & \multirow{3}{*}{.071} \\
\hline & Intermediate & $10(38.5)$ & $3(42.9)$ & $9(31.1)$ & $6(42.8)$ & \\
\hline & Susceptible & $7(26.9)$ & - & $6(20.7)$ & $1(7.1)$ & \\
\hline \multirow{3}{*}{ Nitrofurantoin } & Resistant & $7(26.9)$ & $3(42.9)$ & $9(31.1)$ & $3(21.4)$ & \multirow{3}{*}{.05} \\
\hline & Intermediate & $10(38.5)$ & - & $9(31.1)$ & $6(42.8)$ & \\
\hline & Susceptible & $9(34.6)$ & $4(57.1)$ & 11(37.9) & $5(35.7)$ & \\
\hline
\end{tabular}

$p<.05$ (*significant) 
Table 2) Distribution of MIC of gentamicin and combination form of gentamicin-cetirizine against E. coli isolates

\begin{tabular}{cccc}
\hline \multirow{2}{*}{ Gentamicin-Resistant Isolates } & $\begin{array}{c}\text { Organism Identification } \\
\text { Number }\end{array}$ & \multicolumn{2}{c}{$\mathrm{MIC}\left(\frac{\mu \mathrm{g}}{\mathrm{mL}}\right)$} \\
\cline { 2 - 4 } & $\mathrm{G}$ & $\mathrm{G}+\mathrm{C}$ \\
\hline \multirow{3}{*}{ 14 isolates of $E$. coli } & $\mathrm{EC}_{11}$ & 64 & 4 \\
& $\mathrm{EC}_{17}$ & 64 & 4 \\
& $\mathrm{EC}_{29}$ & 32 & 4 \\
& $\mathrm{EC}_{33}$ & 64 & 4 \\
& $\mathrm{EC}_{27}$ & 64 & 4 \\
& $\mathrm{EC}_{33}$ & 64 & 8 \\
& $\mathrm{EC}_{34}$ & 64 & 4 \\
& $\mathrm{EC}_{45}$ & 64 & 4 \\
$\mathrm{EC}_{49}$ & 64 & 4 \\
$\mathrm{EC}_{56}$ & 64 & 4 \\
$\mathrm{EC}_{63}$ & 64 & 1 \\
$\mathrm{EC}_{67}$ & 64 & 4 \\
$\mathrm{EC}_{69}$ & 32 & 2 \\
$\mathrm{EC}_{72}$ & 64 & 4 \\
\hline
\end{tabular}

Determination of gentamicin minimum inhibitory concentration (MIC): Based on the protocol of the Clinical and Laboratory Standards Institute ${ }^{[10]}$, to prepare the drug stock solution using the microdilution method, gentamicin powder (Sigma-Aldrich, USA) was added to water solution. The antibiotic with an initial concentration was inoculated to 96-well microplates containing Mueller-Hinton broth (Merck, Germany). The MIC of gentamicin at different concentrations of $0.06-64 \mu \mathrm{g} / \mathrm{mL}$ was determined. Then bacterial suspension of gentamicinresistant $E$. coli isolates (with a turbidity of 0.5 McFarland) was separately inoculated into each well. After overnight incubation at $37{ }^{\circ} \mathrm{C}$, the growth rate was measured and compared with positive (without antibiotic) and negative (without bacterial suspension) controls. The inhibitory effect was assessed by reading absorbance at 630 nm using a Plate Reader (BioTec, Germany). The minimum concentration which inhibits bacterial growth up to $90 \%$ in comparison with positive control is considered as MIC $_{90}$.
Determination of MIC of gentamicin in combination with cetirizine: In order to prepare stock solutions, $0.64 \mathrm{~g}$ of cetirizine and gentamicin powders were dissolved in water to obtain a concentration of $64 \mu \mathrm{g} /$ $\mathrm{mL}$. To prepare serial dilutions, $50 \mu \mathrm{L}$ of cetirizine and gentamicin were added to the first well of a 96-well microplate containing $50 \mu \mathrm{L}$ of Mueller-Hinton broth. After adding $50 \mu \mathrm{L}$ of gentamicin-resistant bacterial suspension $\left(1.5 \times 10^{8} \mathrm{CFU} / \mathrm{mL}\right)$ and 24 hours of incubation at $37^{\circ} \mathrm{C}$, MIC values were determined and interpreted.

\section{Findings}

Demographic specifications of bacterial isolates: Among 103 patients with UTI (average age: $48 \pm 21$ years), the highest prevalence rate of infection was observed in individuals $\geq 65$ years of age $(36.36 \%)$, while the lowest prevalence rate of infection (9.09\%) was observed in 15 and 25-year-old patients. Among isolates, 76 (73.8\%) isolates were identified as $E$. coli, most of which were isolated from women (62.1\%) and intensive 
Table 3) Mean MIC of gentamicin and combination form of gentamicin-cetirizine on E. coli isolates

\begin{tabular}{lccc}
\hline $\begin{array}{l}\text { Strains } \\
\mathbf{1 . 5} \times \mathbf{1 0}^{\mathbf{8}} \mathbf{C F U} / \mathbf{m L}\end{array}$ & Gentamicin & Gentamicin - Cetirizine & P-Value \\
\hline $\mathrm{MIC}_{50}(\mu \mathrm{g} / \mathrm{mL})$ & 32 & 1 & .063 \\
$\mathrm{MIC}_{90}(\mu \mathrm{g} / \mathrm{mL})$ & 64 & 4 & $.02^{*}$ \\
\hline
\end{tabular}

$p<.05$ (*significant)

care unit (ICU) patients (38.2\%).

Susceptibility to antibiotics: Based on the antibiotic susceptibility testing results, the frequency of resistance to gentamicin was 14 cases $(18.4 \%)$. The highest rates of resistance and susceptibility were observed against nalidixic acid (average $=44.7 \%$ ) and ceftazidime (average $=48.7 \%$ ), respectively (Table 1).

Minimum inhibitory concentration: Evaluation of the effects of different concentrations of gentamicin (0.06-64 $\mu \mathrm{g}$ / $\mathrm{mL}$ ) on the growth of $E$. coli strains showed that the most significant growth changes occurred at concentrations of 4 and $8 \mu \mathrm{g} / \mathrm{mL}$. According to Table 2-3, the concentration of gentamicin in combination with cetirizine, inhibiting $90 \%$ of $E$. coli isolates $\left(\mathrm{MIC}_{90}\right.$ ), was $4 \mu \mathrm{g} / \mathrm{mL}$, which was 16 times lower than that of gentamicin alone $\left(\mathrm{MIC}_{90}=64 \mu \mathrm{g} / \mathrm{mL}\right)$ $(p=.02)$.

\section{Discussion}

With the emergence of multidrugresistant bacteria, the management of infections caused by $E$. coli strains has become challenging in the community. Epidemiological studies have shown that the Enterobacteriaceae family is the most important group of bacteria isolated from UTIs, and E. coli accounting for more than $75 \%$ of UTIs is the main leading cause of these infections ${ }^{[11]}$. In this study, out of a total of $76 \mathrm{E}$. coli isolates, $62.1 \%$ were separated from women, and older groups were more infected. In studies conducted in Iran in $2013^{\text {[12] }}$ and $2017^{\text {[13] }}$, UTIs were shown to be more common in women than in men, which is consistent with the results of this study. Another variable in this study was different hospital wards. The results of the present study showed that the most E. coli isolates (38.2\%) were isolated from the ICU ward, which is consistent with the results of a previous study in Iran in $2012^{[14]}$. It seems that long-term hospitalization in this ward, the patient's serious condition, the use of invasive therapeutic tools such as tracheal tube, ventilator, and urinary catheter are among the main reasons for the prevalence of resistant organisms in this ward [15]. Today, one of the most significant global health problems is the increasing prevalence of antibiotic-resistant pathogens in humans. The main cause of increased resistance in pathogenic bacteria is the overuse of antibiotics, leading to the emergence and spread of resistant pathogens ${ }^{[3]}$. In the present study, nalidixic acid had the least effect, while gentamicin had a moderate effect on $E$. coli isolates, similar to a study in Iran in $2015^{[16]}$. Accordingly, the isolation of $E$. coli strains from nosocomial infections, especially UTIs, was put on the agenda of this study to investigate the behavior of these bacteria in relation to antibiotics and the use of new ways. In combination with other antibiotics synergistically, the treatment protocol could be improved by increasing the effectiveness of the drug and reducing the effective dose of the drug.

Extensive studies by researchers around the 
world have reported antimicrobial effects of a variety of drugs belonging to different classes of non-antibiotic drugs such as antihistamines 'bromodiphenhydramine (Bromazine) and diphenhydramine', all of which have shown antimicrobial effects of various drugs from the past to the present. Cetirizine dihydrochloride is one of these non-antibiotic drugs, which inhibits the effect of histamine on $\mathrm{H} 1$ receptor of muscles [17-18]. Evaluation of the minimum inhibitory concentration (MIC) of gentamicin-cetirizine combination against $E$. coli isolates showed that with increasing the concentration from 2 to $4 \mu \mathrm{g} / \mathrm{mL}$, the inhibitory power of the antibiotic increased. In a study by Martins et al. (2008), cetirizine was introduced as an antibacterial agent with inhibitory effects against Staphylococcus aureus and Salmonella typhi ${ }^{[19]}$. Based on experiments conducted by Maji et al. (2017), it was found that cetirizine at a concentration of $1000 \mu \mathrm{g} / \mathrm{mL}$ has more inhibitory effects against $E$. coli isolates ${ }^{[20]}$, which was lower than that of a wide range of antibiotics, and its effectiveness was evaluated as more effective. In another study, ibuprofenfluconazole combination was shown to be more potent against candidiasis as a fungal infection ${ }^{[21]}$.

\section{Conclusion}

Improper use of antibiotics in recent years and lack of awareness of proper use have caused many problems due to their effects and especially the emergence of multidrugresistant bacteria. It was found that the combined use of gentamicin with cetirizine has a greater inhibitory effect than the use of gentamicin alone. It seems that alternative way for controlling drug-resistant bacteria is the combined use of non-antibiotics and antibiotics with synergistic effects. Therefore, the use of this combination requires more attention and research in order to minimize the rate of UTIs in the future.

Acknowledgements: This article was extracted from a MSc thesis conducted by Leila Hasani and supported by the Research Council of the Islamic Azad University of Gorgan, Iran. The authors are grateful to all those who assisted them in this study.

Ethical Permissions: We hereby declare that all ethical standards were respected in the preparation of the submitted article.

Conflicts of Interests: None declared.

Authors' Contribution: Conceptualization: LF; Data curation and formal analysis: LF; Investigation: LF, LH; Methodology and project administration: LF, LH; Supervision: LF; Validation: LF; Writing of original draft: LF, LH; Writing, reviewing, and editing: LF, LH.

Fundings: No financial interests related to the content of this manuscript are declared. Consent to participate: A written informed consent was obtained from all patients.

\section{References}

1. Chew KL, La MV, Lin RT, Teo JW. Colistin and polymyxin B susceptibility testing for carbapenem-resistant and mcr-positive Enterobacteriaceae: Comparison of Sensititre, MicroScan, Vitek 2, and Etest with broth microdilution. J Clin Microbiol. 2017;55(9):2609-16.

2. Flores-Mireles AL, Walker JN, Capron M, Hultgren SJ. Urinary tract infections: Epidemiology, mechanisms of infection, and treatment options. Nat Rev Microbiol. 2015;13(5):269-84.

3. Foxman B. The epidemiology of urinary tract infection. Nat Rev Urol. 2010;7(12):653-60.

4. Jain S, Khety Z. Changing antimicrobial resistance pattern of isolates from an ICU over a 2 year period. J Assoc Phys India. 2012; 60:27-8.

5. Nesta B, Spraggon G, Alteri C, Gomes 
Moriel D, Rosini R, Veggi D, et al. FdeC, a novel broadly conserved Escherichia coli adhesin eliciting protection against urinary tract infections. MBio, 2012;3 (2):e00010-12.

6. Abdi HA, Rashki A. Comparison of virulence factors distribution in uropathogenic E. coli isolates from phylogenetic groups B2 and D. Int J Enteric Pathog. 2014; 2(4): e21725.

7. Annadurai S, Guhathakurta A, Sa B, Dastidar SG, Roy R, Chakraborty AN. Experimental studies on synergism between aminoglycosides and the antimicrobial anti-inflammatory agent diclofenac sodium. J Chemother. 2002;14(1):47-53.

8. Kalayci S. Antimicrobial properties of various nonantibiotic drugs against microorganisms. J Bioanal Biomed. 2016;8(4):1120-4.

9. Manuselis M. Textbook of diagnostic microbiology. 5th edition. Saunders; 2015.

10. Clinical and Laboratory Standards Institute. M100-S25: Performance standards for antimicrobial 324 susceptibility testing; Twenty-fifth informational supplement. Wayne, PA: Clinical and Laboratory Standards Institute, 2015, 325.

11. Abe CM, Salvador FA, Falsetti IN, Vieira MA, Blanco J, Blanco JE, et al. Uropathogenic Escherichia coli (UPEC) strains may carry virulence properties of diarrhoeagenic E. coli. FEMS Immunol Med Microbiol. 2008;52(3):397-406.

12. Pourmand M, Keshtvarz M, Soltan Dallal M, Talebi M, Bakhtiari R, Pourmand G. Urinary tract infection in renal transplant patients in Sina University Hospital. Tehran Univ Med J. 2013;71(2):114-21.

13. Keikha M, Rava M. Trend of antibiotic resistance of Escherichia coli strains isolated from urinary tract infections in outpatients referring to Nabi Akram hospital in Zahedan. J Paramed Sci Rehabil. 2017;6(4):73-8.

14. Neamati F, Firoozeh F, Saffary M, Mousavi SGA. The prevalence of uropathogenic E. coli and detection of some virulence genes isolated from patients referred to Kashan Shahid-Beheshti hospital during 2012-2013. Feyz. 2014;18 (3):267-74.

15. Slavchev G, Pisareva E, Markova N. Virulence of uropathogenic Escherichia coli. J Cult Collect. 2009;6:3-9.

16. Asadpour Rahimabadi K, Hashemitabar G, Mojtahedi A. Antibiotic-resistance patterns in E. coli isolated from patients with urinary tract infection in Rasht. J Guilan Univ Med Sci. 2016;24(96):22-9.

17. Perlmutter JI, Forbes LT, Krysan DJ, Ebsworth M, Colgufoun JM, Wang JL, et al. Repurposing the antihistamine terfenadine for antimicrobial activity against $\mathrm{S}$. aureus. J Med Chem. 2014;57(20):8540-62.

18. Dutta NK, Mazumdar K, Dastidar SG, Park $\mathrm{JH}$. Activity of diclofenac used alone and in combination with streptomycin against Mycobacterium tuberculosis in mice. Int J Antimicrob Agents. 2007;30(4):336-40.

19. Martins M, Dastidar SG, Fanning S, Kristiansen JE, Molnar J, Pages JM, et al. Potential role of non-antibiotics (helper compounds) in the treatment of multidrug resistant Gram negative infections: Mechanism for their direct and indirect activities. Int J Antimicrob Agents. 2008;31(3):198-208.

20. Maji HS, Maji S, Bhattacharya M. An exploratory study on the antimicrobial activity of cetirizine dihydrochloride. Indian J Pharm Sci. 2017;79(5):751-7.

21. Shamooshaki T, Fozouni L. Fluconazole and ibuprofen combination: A potential treatment for mucosal candidiasis. MLJ. 2020;14(5):25-9. 